\title{
PENGEMBANGAN VIDEO PERANCANGAN DAN PELAKSANAAN PRAKTIKUM BIOLOGI
}

\author{
Oktavia Safitri $^{1)}$, Evi Suryawati ${ }^{2)}$, Darmadi $^{3)}$, \\ E-mail: oktavia.safitri5013@ student.unri.ac.id \\ ${ }^{12) 3)}$ Program Studi Pendidikan Biologi, FKIP Universitas Riau
}

\begin{abstract}
Regulation of the Minister of National Education of the Republic of Indonesia Number 16 of 2007 concerning Academic Qualification Standards and Teacher Competencies states that one of the competencies of high school biology teachers is the competence to properly design and implement practicum. Biology Education students as prospective biology teachers must master these competencies. The existence of independent learning resources can be used as a reference for prospective student teachers in studying material related to practicum activities. This study aims to produce independent learning resources in the form of videos. This research was conducted at the PMIPA Laboratory FKIP Riau University, SMAN 8 Pekanbaru and SMAN 15 Pekanbaru in AprilDecember 2020. The type of research used was Research and Development (R\&D) with the ADDIE model (Analyze, Design, Development, Implementation and Evaluation). The stages in this research include analysis, design, and development. The instruments used in this study were the validation sheet and response questionnaire. The results of the video validation obtained an average value of 3.57 with a very valid category. The results of the limited trial phase I obtained an average value of 3.64 in the very good category, while the results of the phase II trial obtained an average value of 3.43 in the very good category. Based on the results of the validation and trials, it shows that the video of the design and implementation of the biology practicum developed can be used as an independent learning resource for prospective biology teachers.
\end{abstract}

Keywords: Design, Implementation, Practicum, Video.

\section{PENDAHULUAN}

Pengetahuan tentang bagaimana
mengembangkan pembelajaran dengan metode praktikum adalah bagian dari Pedagogical Content Knowledge (PCK) yang merupakan salah satu modal awal mahasiswa untuk menjadi guru biologi profesional (Putri Agustina, et al. 2016). Peraturan Menteri Pendidikan Nasional Republik Indonesia Nomor 16 Tahun 2007 tentang Standar Kualifikasi Akademik dan Kompetensi Guru menyebutkan bahwa salah satu kompetensi guru mata pelajaran biologi SMA/MA adalah kompetensi dalam merancang eksperimen biologi untuk keperluan pembelajaran atau penelitian dan kompetensi dalam melaksanakan eksperimen biologi dengan cara yang benar. Berdasarkan hasil penelitian yang dilakukan Sofyan Anif (2013) pada 116 orang guru biologi pasca sertifikasi di Karesidenan Surakara menunjukkan bahwa indikator merancang eksperimen biologi dan melaksanakan eksperimen biologi masih tergolong rendah yakni dengan daya serap 29,89\% untuk indikator merancang ekperimen biologi dan 43,10\% untuk indikator melaksanakan ekperimen biologi dengan benar.

Rendahnya kompetensi berkaitan dengan kegiatan praktikum tidak hanya dijumpai pada guru biologi, namun juga terlihat pada mahasiswa pendidikan biologi yang pada hakikatnya dipersiapkan untuk menjadi seorang guru biologi profesional. Berdasarkan hasil penelitian Djohar Maknun (2015) pada mahasiswa Jurusan Tadris IPA 
Biologi IAIN Syekh Nurjati Cirebon pada mata kuliah Praktek Pengalaman Lapangan (PPL) II ditemukan sejumlah kesulitan mahasiswa ketika mengikuti kegiatan laboratorium/praktikum dan dari angket diperoleh hasil sebanyak $85 \%$ mahasiswa menyatakan belum mengetahui dan memahami kompetensi dasar kegiatan laboratorium. Kemudian berdasarkan penelitian Shofia Nur Mutmainnah, et al. (2019) yang dilakukan kepada 52 mahasiswa semester 2 di salah satu Universitas Surakarta diketahui bahwa kemampuan merancang percobaan mahasiswa berada dalam kategori sedang yakni $62,96 \%$. Hasil penelitian tersebut menunjukkan mahasiswa calon guru biologi belum mampu dalam merancang dan melaksanakan kegiatan praktikum dengan baik.

Upaya yang dapat dilakukan untuk meningkatkan pengetahuan mahasiswa calon guru biologi dalam merancang dan melaksanakan kegiatan praktikum salah satunya yaitu dengan memanfaatkan sumber belajar. Menurut Arifah Novia Arifin, et al. (2019) sumber belajar adalah semua sumber baik berupa data, orang dan wujud tertentu yang dapat digunakan untuk mencapai tujuan belajar atau mencapai kompetensi tertentu. Salah satu bentuk sumber belajar yang dapat digunakan adalah video pembelajaran. Menurut Gde Putu Arya Oka (2017), video merupakan suatu teknologi pemrosesan sinyal elektronik yang mampu menampilkan gambar bergerak dan suara. Penggunaan video praktikum ini memiliki beberapa kelebihan yakni (1) video yang dapat diputar berulangulang dimana saja dan kapan saja, (2) video dapat digunakan secara individual sehingga dapat digunakan sebagai sumber belajar mandiri, (3) mudah dioperasikan pada aplikasi bawaan komputer maupun handphone, dan (4) dapat menarik perhatian pengguna.

Penelitian ini bertujuan untuk
menghasilkan video perancangan dan
pelaksanaaan praktikum biologi yang
berkualitas sehingga dapat bermanfaat
sebagai sumber belajar mandiri bagi
mahasiswa calon guru biologi.

\section{METODE PENELITIAN}

Penelitian ini dilaksanakan di Laboratorium PMIPA FKIP Univeritas Riau, SMAN 8 Pekanbaru dan SMAN 15 Pekanbaru pada bulan April-Desember 2020. Jenis penelitian yang digunakan merupakan Research and Development (R\&D). Pada penelitian ini hanya sampai pada tahap Development (Pengembangan). Data dikumpulkan dengan menggunakan lembar validasi dan angket respon. Validasi terdiri 4 aspek yakni aspek materi, bahasa, kualitas video dan penyajian. Validasi produk dilakukan oleh 5 orang validator yang terdiri dari 3 orang dosen pendidikan biologi dan 2 orang guru biologi profesional. Uji coba produk dilakukan dengan memberi angket respon kepada mahasiswa calon guru biologi yakni mahasiswa Pendidikan Biologi Universitas Riau semester VII.

Data yang diperoleh dilakukan analisis secara deskriptif kualitatif. Adapun kategori penilaian untuk validasi dan angket respon dapat dilihat pada Tabel 1.

Tabel 1. Kategori Penilaian

\begin{tabular}{ccc}
\hline No & Skor Penilaian & Kategori \\
\hline 1. & 4 & Sangat Setuju (SS) \\
\hline 2. & 3 & Setuju (S) \\
\hline 3. & 2 & Kurang Setuju (KS) \\
\hline 4. & 1 & Tidak Setuju (TS) \\
\hline
\end{tabular}

Data yang diperoleh kemudian dianalisis menggunakan rumus :

$\mathrm{M}=\frac{\sum F x}{\mathrm{~N}}$

Keterangan :

$\mathrm{M}=$ Rata-rata penilaian

$\mathrm{Fx}=$ Skor yang diperoleh

$\mathrm{N}=$ Jumlah komponen yang divalidasi

Kriteria dalam mengambil keputusan hasil validasi dapat dilihat pada Tabel 2 .

Tabel 2. Kriteria Validitas

\begin{tabular}{cc}
\hline $\begin{array}{c}\text { Interval Rata-Rata } \\
\text { Nilai }\end{array}$ & Kategori \\
\hline $3,25 \leq \mathrm{x} \leq 4$ & Sangat valid \\
\hline $2,5 \leq \mathrm{x}<3,25$ & Valid \\
\hline $1,75 \leq \mathrm{x}<2,5$ & Kurang valid \\
\hline $1 \leq \mathrm{x}<1,75$ & Tidak valid \\
\hline & (Sugiyono, 2016)
\end{tabular}


Sedangkan kriteria hasil uji coba terbatas dapat dilihat pada Tabel 3 .

Tabel 3. Kategori Penilaian Angket Respon

\begin{tabular}{ccc}
\hline No & Kategori & Skor \\
\hline 1. & Sangat Setuju (SS) & 4 \\
\hline 2. & Setuju (S) & 3 \\
\hline 3. & Kurang Setuju (KS) & 2 \\
\hline 4. & Tidak Setuju (TS) & 1 \\
\hline & & (Sugiyono, 2016)
\end{tabular}

(Sugiyono, 2016)

\section{HASIL DAN PEMBAHASAN}

\section{Validitas Video}

Validasi video terdiri dari 4 aspek. Keempat aspek ini meliputi aspek materi, aspek bahasa, aspek kualitas video, dan aspek penyajian.

\section{A. Aspek Materi}

Adapun hasil validasi video pada aspek materi dapat dilihat pada Tabel 4.

\section{Tabel 4. Hasil Validasi Aspek Materi}

\begin{tabular}{clcc}
\hline No & \multicolumn{1}{c}{ Item Pernyataan } & $\begin{array}{c}\text { Rata- } \\
\text { rata }\end{array}$ & Ktg \\
\hline 1 & $\begin{array}{l}\text { Kebenaran konsep pada } \\
\text { video }\end{array}$ & 3,80 & $\mathrm{SV}$ \\
\hline 2 & $\begin{array}{l}\text { Kesuaian gambar pada video } \\
\text { dengan materi }\end{array}$ & 3,60 & $\mathrm{SV}$ \\
\hline 3 & $\begin{array}{l}\text { Penyampaian materi pada } \\
\text { video sistematis }\end{array}$ & 3,80 & $\mathrm{SV}$ \\
\hline 4 & $\begin{array}{l}\text { Video memudahkan dalam } \\
\text { memahami konsep } \\
\text { perancangan dan } \\
\text { pelaksanaan praktikum } \\
\text { biologi sekolah }\end{array}$ & 3,20 & $\mathrm{~V}$ \\
\hline 5 & $\begin{array}{l}\text { Kesuaian materi pada video } \\
\text { dengan kompetensi dasar } \\
\text { dan indikator esensial } \\
\text { content knowledge yang } \\
\text { harus dikuasai oleh guru } \\
\text { biologi }\end{array}$ & 3,60 & $\mathrm{SV}$ \\
\hline 6 & Isi video mudah dimengerti & 3,80 & $\mathrm{SV}$ \\
\hline 7 & $\begin{array}{l}\text { Video meningkatkan } \\
\text { kemandirian belajar pada } \\
\text { kegiatan perancangan dan } \\
\text { pelaksanaan praktikum } \\
\text { biologi sekolah }\end{array}$ & 3,20 & $\mathrm{~V}$ \\
\hline 8 & $\begin{array}{l}\text { Video bermanfaat sebagai } \\
\text { sumber belajar }\end{array}$ & 3,80 & $\mathrm{SV}$ \\
\hline & \multicolumn{1}{c}{ Rata-rata } & $\mathbf{3 , 6 0}$ & $\mathbf{S V}$ \\
\hline & & & \\
\hline & & & \\
\hline
\end{tabular}

Rata-rata nilai validasi video berada pada ketegori sangat valid (Tabel 4). Hal ini menunjukkan bahwa materi yang disajikan dalam video sudah sesuai dengan konsep perancangan dan pelaksanaan praktikum yang benar. Pengembangan suatu sumber belajar, aspek materi merupakan hal yang paling penting. Oleh karena itu, kebenaran konsep dari materi yang disampaikan harus dapat dipertanggungjawabkan. Sebagaimana yang dikemukakan Hamdan Husein Batubara, (2020), konsep-konsep yang dijelaskan di dalam video juga perlu dipastikan kebenaran agar pengguna tidak memperoleh informasi yang menyesatkan, usang, dan tidak sesuai dengan tujuan pembelajaran.

Materi yang disampaikan pada video yang dikembangkan disajikan secara sistematis agar isi/pesan yang disampaikan dapat diterima dengan mudah oleh pengguna. Menurut Rahmi Ramadhani, et al. (2020), materi yang tersusun secara sistematis dan mempunyai ruang lingkup yang jelas dapat dengan mudah dimengerti. Secara keseluruhan materi pada video visualisasi dapat membantu pengguna dalam memahami konsep perancangan dan pelaksanaan praktikum biologi. Menurut Sherin, et al. (2017) video pembelajaran bertujuan membantu mengomunikasikan pesan agar memberikan pemahaman kepada penerima pesan. Jika video menyajikan materi yang benar dan mudah dimengerti, maka video dapat dimanfaatkan sebagai sumber belajar. Menurut Muhammad Yaumi (2018) jika video berisi materi atau bahan pembelajaran untuk membantu proses pembelajaran baik dalam maupun luar ruang kelas maka kedudukannya sama dengan sumber belajar.

\section{B. Aspek Bahasa}

Adapun hasil validasi video pada aspek bahasa dapat dilihat pada Tabel 5 .

Tabel 5. Hasil Validasi Aspek Bahasa

\begin{tabular}{clcc}
\hline No & \multicolumn{1}{c}{ Item Pernyataan } & $\begin{array}{c}\text { Rata- } \\
\text { rata }\end{array}$ & Ktg \\
\hline 1 & $\begin{array}{l}\text { Penggunaan bahasa sesuai } \\
\text { EYD }\end{array}$ & 3,40 & $\mathrm{SV}$ \\
\hline 2 & $\begin{array}{l}\text { Penggunaan bahasa pada } \\
\text { video komunikatif }\end{array}$ & 3,80 & $\mathrm{SV}$ \\
\hline 3 & $\begin{array}{l}\text { Pelafalan kata pada video } \\
\text { terdengar jelas }\end{array}$ & 3,60 & $\mathrm{SV}$ \\
\hline \multicolumn{1}{c}{ Rata-rata } & $\mathbf{3 , 6 0}$ & $\mathrm{SV}$ \\
\hline
\end{tabular}


Rata-rata nilai validasi video pada aspek bahasa berada pada ketegori sangat valid (Tabel 5). Hal ini menunjukkan bahwa bahasa yang digunakan pada video sudah sesuai dengan Bahasa Indonesia yang baik dan benar. Menurut Marinda Sari Sofiyana (2016) bahasa adalah sarana untuk menyerap dan mengembangkan pengetahuan. Oleh karena itu, penggunaan bahasa dalam mengembangkan suatu video juga harus diperhatikan.

Video merupakan media yang menyajikan informasi melalui visual, juga disertai dengan suara/audio. Suara pada video visualisasi bersumber dari narasi presenter dan dubbing. Narasi yang disampaikan pada video sudah diatur dengan kalimat yang jelas sehingga tidak membingungkan pengguna. Bahasa yang dipilih merupakan bahasa yang umum dan familiar didengar. Menurut Ida Sari Rahmawati, et al. (2016) penataan kalimat dalam media pembelajaran haruslah komunikatif yakni tidak bertele-tele sehingga mudah dipahami.

\section{Aspek Kualitas Video}

Adapun hasil validasi pada aspek kualitas video dapat dilihat pada Tabel 6.

Tabel 6. Hasil Validasi Aspek Kualitas Video.

\begin{tabular}{|c|c|c|c|}
\hline No & Item Pernyataan & $\begin{array}{c}\text { Rata- } \\
\text { rata }\end{array}$ & Ktg \\
\hline 1 & $\begin{array}{l}\text { Video memiliki kefokusan yang } \\
\text { jelas }\end{array}$ & 3,60 & SV \\
\hline 2 & $\begin{array}{l}\text { Kualitas gambar pada video } \\
\text { baik }\end{array}$ & 3,40 & SV \\
\hline 3 & $\begin{array}{l}\text { Ukuran huruf yang digunakan } \\
\text { tepat dan mudah dibaca }\end{array}$ & 3,80 & SV \\
\hline 4 & $\begin{array}{l}\text { Jenis huruf yang digunakan } \\
\text { sudah tepat }\end{array}$ & 3,40 & SV \\
\hline 5 & $\begin{array}{l}\text { Keserasian warna huruf dengan } \\
\text { warna latar (background) }\end{array}$ & 3,40 & SV \\
\hline 6 & $\begin{array}{l}\text { Proporsi gambar dan tulisan } \\
\text { pada video tepat }\end{array}$ & 3,60 & SV \\
\hline 7 & $\begin{array}{l}\text { Suara pada video terdengar } \\
\text { jelas }\end{array}$ & 3,60 & SV \\
\hline 8 & $\begin{array}{l}\text { Volume musik pengiring } \\
\text { (backsound) yang digunakan } \\
\text { tepat }\end{array}$ & 3,40 & SV \\
\hline \multirow[t]{2}{*}{9} & Pencahayaan pada video sesuai & 3,40 & SV \\
\hline & Rata-rata & $3, \mathbf{5 1}$ & SV \\
\hline
\end{tabular}

Rata-rata nilai validasi video pada aspek kualitas video berada pada ketegori sangat valid (Tabel 6). Hal ini menunjukkan bahwa hasil video yang dikembangkan sudah memiliki kualitas yang baik dari segi visual maupun audio. Salah satu hal yang harus diperhatikan dalam proses pengambilan video adalah kefokusan gambar. Sebagaimana yang dikemukakan oleh Dominikus Juju (2006), bahwa video yang bagus harus memperhatikan beberapa hal, salah satunya adalah kefokusan saat pengambilan gambar. Video yang memiliki fokus yang jelas akan memberikan kesan visual yang menarik.

Video visualisasi ini bukan hanya menyajikan suara/audio saja, namun video visualisasi juga dilengkapi dengan gambar disertai dengan tulisan. Menurut Benny A. Pribadi, (2017), ukuran huruf yang jelas sangat berpengaruh terhadap kemampuan pemirsa dalam melihat dan membaca informasi yang ditayangkan.

Audio merupakan salah satu komponen penting dalam pembelajaran khususnya saat menggunakan sumber belajar dalam bentuk video. Audio berperan besar untuk memperjelas maupun mempertegas penyampaian pesan atau informasi. Mengingat pentingnya peran audio pada suatu video, maka suara dari audio tersebut haruslah terdengar dengan jelas. Menurut Hamdan Husein Batubara, (2020), tampilan audio yang berkualitas pada video pembelajaran dapat dinilai dari kejernihan suaranya.

Video ini juga dilengkapi dengan musik pengiring (backsound). Musik pengiring (backsound) yang dipilih adalah musik instrumental. Tujuannya untuk menambah nuansa tertentu ke dalam video sehingga video menjadi lebih menarik. Selain itu, menurut Su Rahma, (2018), backsound juga berguna untuk menutupi suara-suara berisik (noise) yang muncul saat proses perekaman video. Volume backsound pada video yang dikembangkan telah disesuaikan agar tidak mengganggu audio utama video. Pada video yang dikembangkan volume musik pengiring (backsound) yang digunakan diatur lebih kecil daripada volume audio utama. 
Pencahayaan pada saat proses pengambilan video sangat dijaga semaksimal mungkin agar hasil dari rekaman memiliki kualitas yang baik. Perekaman video dilakukan di tempat yang memiliki intensitas penerangan yang bagus. Menurut Wahana Komputer (2008), jika kondisi saat perekaman minim cahaya maka akan membuat kamera mengompensasinya dengan memperlambat kecepatan proses rekaman sehingga resolusi gambar menjadi turun dan akan tampak butiran kasar.

\section{Aspek Penyajian}

Adapun hasil validasi pada aspek penyajian dapat dilihat pada Tabel 7.

Tabel 7. Hasil Validasi Aspek Penyajian

\begin{tabular}{clcc}
\hline No & \multicolumn{1}{c}{ Item Pernyataan } & $\begin{array}{c}\text { Rata- } \\
\text { rata }\end{array}$ & Ktg \\
\hline 1 & Tampilan video menarik & 3,60 & $\mathrm{SV}$ \\
\hline 2 & $\begin{array}{l}\text { Penyajian praktikum } \\
\text { menarik }\end{array}$ & 3,60 & $\mathrm{SV}$ \\
\hline 3 & $\begin{array}{l}\text { Video dapat dijalankan } \\
\text { diberbagai software dan } \\
\text { hardware yang ada }\end{array}$ & 3,60 & $\mathrm{SV}$ \\
\hline 4. & $\begin{array}{l}\text { Kemudahan } \\
\text { pengoperasian/penggunaan } \\
\text { video }\end{array}$ & 3,40 & $\mathrm{SV}$ \\
\hline \multicolumn{2}{c}{ Rata-rata } & $\mathbf{3 , 5 5}$ & $\mathbf{S V}$ \\
\hline
\end{tabular}

Rata-rata nilai validasi video pada aspek penyajian berada pada ketegori sangat valid (Tabel 7). Video hasil pengembangan disajikan dengan memasukkan berbagai unsur seperti gambar, animasi, efek transisi, dan musik pengiring sehingga membuat tampilan video tidak membosankan. Menurut Arsad Bahri, et al. (2018), pembelajaran yang menarik apabila penjelasan materi disajikan dengan tampilan yang mengesankan dalam bentuk gambar-gambar dan animasi.

Hasil akhir dari video di-export dalam bentuk .MP4 sehingga mudah untuk diputar diperangkat mana saja dan mudah dioperasikan pengguna tanpa perlu keahlian khusus. Sebagaimana yang dikemukakan Jubilee Enterprise (2013), bahwa MP4 merupakan format yang mengkombinasikan konten audio dengan video dalam satu file yang cenderung memiliki ukuran kecil sehingga dapat dimainkan pada banyak perangkat atau gadget di pasaran. Pengguna hanya perlu memutar video pada aplikasi pemutar video bawaan pada perangkat laptop atau handphone tanpa perlu menginstal aplikasi lainnya.

\section{Hasil Uji Coba Video}

Uji coba terbatas menggunakan lembar angket respon digunakan untuk mengetahui respon atau tanggapan responden terhadap keterpakaian video dikembangkan. Adapun hasil uji coba dapat dilihat pada Tabel 8.

Tabel 8. Hasil Rata-rata Uji Coba Video

\begin{tabular}{ccc}
\hline Uji Coba Tahap & Rata-rata & Kategori \\
\hline I & 3,64 & SB \\
\hline II & 3,43 & SB \\
\hline
\end{tabular}

Rata-rata nilai hasil uji coba I dan II pada video yang dikembangkan berada pada ketegori sangat baik (Tabel 8). Hal ini menunjukkan bahwa mahasiswa calon guru biologi memberikan respon positif, dimana video yang dikembangkan mendapat respon sangat baik karena responden merasa mudah untuk mempelajari materi perancangan dan pelaksanaan praktikum melalui video. Menurut Pusvyta Sari, (2019), jenis media audio visual bisa digunakan oleh anak yang memiliki kecenderungan gaya belajar dengan dua modalitas indrawi sekaligus, yaitu audio dan visual. Hal ini menunjukkan bahwa sumber belajar dengan menggunakan video dapat memfasilitasi dua gaya belajar siswa sekaligus.

Responden akan mudah memahami pesan atau informasi yang terdapat di dalam video karena mereka melihat visualisasi dan mendengar sekaligus. Menurut Sherin (2017), video pembelajaran bertujuan membantu mengomunikasikan pesan-pesan yang disampaikan dapat lebih memberikan pemahaman kepada penerima pesan.

\section{KESIMPULAN}

Video perancangan dan pelaksanaan praktikum biologi yang dikembangkan berkualitas dan dapat dijadikan sebagai 
sumber belajar mandiri bagi mahasiswa calon guru biologi. Rekomendasi yang diberikan peneliti yakni produk visualisasi berupa video dan buku panduan dapat dijadikan sebagai referensi sumber belajar mandiri dan kepada peneliti selanjutnya dapat melanjutkan tahapan berikutnya dari penelitian pengembangan yaitu implementasi dan evaluasi.

\section{DAFTAR PUSTAKA}

Arifah Novia Arifin, Arsad Bahri, Muhiddin Palennari, dan Yogi Saputra. 2019. Pengembangan Sumber Belajar Genetika Berbasis E-Magazine Bagi Siswa SMA. Prosiding Seminar Nasional LP2M UNM Edisi 7. 16 November 2019. Universitas Negeri Makassar.

Arsad Bahri, Wahyu Hidayat dan Abdul Qalam Muntaha. 2018. Penggunaan Media Berbasis AutoPlay Media Studio 8 untuk Meningkatkan Aktivitas dan Hasil Belajar Siswa: Sebuah Inovasi Media Pembelajaran. Proceeding Biology Education Conference. 1 Oktober 2018. Universitas Sebelas Maret. Surakarta. 15(1): 394-402.

BSNP. 2007. Peraturan Menteri Pendidikan Nasional Nomor 16 Tahun 2007 tentang Standar Kualifikasi Akademik dan Kompetensi Guru. https://bsnpindonesia.org/nomor-16-tahun-2007/ (diakses 20 Januari 2020).

Benny A. Pribadi. 2017. Media dan Teknologi dalam Pembelajaran. Jakarta: Kencana. Google Play.

Djohar Maknun. 2015. Evaluasi Keterampilan Laboratorium Mahasiswa Menggunakan Asesmen Kegiatan Laboratorium Berbasis Kompetensi ada Pelaksanaan Praktek Pengalaman Lapangan. Jurnal Tarbiyah. 22(1): 21-47.

Dominikus Juju. 2006. Membuat Video Klip dengan Ulead VideoStudio 8 \& Ulead Cool 3D. Jakarta: PT Elex Media
Komputindo. Google Play.

Gde Putu Arya Oka. 2017. Media dan Multimedia Pembelajaran. Yogyakarta: Deepublish. Google Play.

Hamdan Husein Batubara. 2020. Media Pembelajaran Efektif. Semarang: Fatawa Publishing. Google Play.

Ida Sari Rahmawati, Roekhan, dan Nurchasanah. 2016. Pengembangan Media Pembelajaran Menulis Teks Fabel Dengan Macromedia Flash Bagi Siswa SMP. Jurnal Pendidikan. 1(7): 1323-1329.

Jubilee Enterprise. 2013. Rahasia Menjadi Jago Download. Jakarta: Elex Media Komputindo. Google Play.

Marinda Sari Sofiyana, Fatchur Rohman, dan Murni Saptasari. 2016. Pengembangan Buku Referensi Bioekologi Berdasarkan Kajian Struktur Komunitas Lumut Epifit Di Taman Nasional Bromo Tengger Semeru. Jurnal Konstruktivisme. 8(2): 117-130.

Muhammad Yaumi. 2018. Media dan Teknologi Pembelajaran. Jakarta: Prenada Media Group. Google Play.

Pusvyta Sari. 2019. Analisis Terhadap Kerucut Pengalaman Edgar Dale dan Keragaman Gaya Belajar Untuk Memilih Media Yang Tepat dalam Pembelajaran. Jurnal Manajemen Pendidikan. 1(1): 5878.

Putri Agustina, Puput Putri Kus Sundari, dan Dewi Eri Ardani. 2016. Kemampuan Mahasiswa Calon Guru Biologi dalam Merancang Pembelajaran Berbasis Praktikum: Studi Kasus Mahasiswa Pendidikan Biologi FKIP UMS. Prosiding Seminar Nasional XII Biologi. 1 Oktober 2016. FKIP Universitas Sebelas Maret. Surakarta. 
Rahmi Lestari Helmi, Siti Kania Kushadiani, Meita Safitiri, Rusli Faizi, Dhevi E.I R. Mahelingga, Junaedi Mulawardana, M. Fadly Suhendra, Risma Wahyu Hartiningsih, Noviasatuti Putri I, Sonny Haru Kusuma, Rahma Hilma Taslima, Prapti Sasiwi, Sarwendah Puspita Dewi, dan Martinus Helmiawan. 2017. Pedoman Penerbitan Buku LIPI Press. Jakarta: LIPI Press. Google Play.

Sherin, Miriam G. and Dyer, Elizabeth B. 2017. Teacher self-captured video:learning to see. Journal of Phi Delta Kappan. 98(7): 49-54.

Shofia Nur Mutmainnah, Kusnia Padmawati, Nella Puspitasari, dan Baskoro Adi Prayitno. 2019. Profil Keterampilan Proses Sains (KPS) Mahasiswa Pendidikan
Biologi Ditinjau dari Kemampuan Akademik. Jurnal Penelitian Pendidikan Biologi. 3(1): 49-56.

Sofyan Anif. 2013. Profil Kompetensi Profesional Guru Mapel Biologi Pasca Sertifikasi di Karesidenan Surakarta. Jurnal Varia Pendidikan. 25(2): 205-223.

Su Rahman. 2018. Panduan Editing Video ala Pro dengan Software Gratis. Jakarta: PT Alex Media Komputindo. Google Play.

Wahana Komputer. 2008. Video Editing dan Video Production. Jakarta: PT Alex Media Komputindo. 